\title{
Be Able To Perform a Clinical Activity
}

National Cancer Institute

\section{Source}

National Cancer Institute. Be Able To Perform a Clinical Activity. NCI Thesaurus. Code C128496.

The healthcare provider or setting must have the ability to carry out a particular clinical activity, such as administer a particular treatment, diagnose a particular disease, or recognize a particular adverse event. 